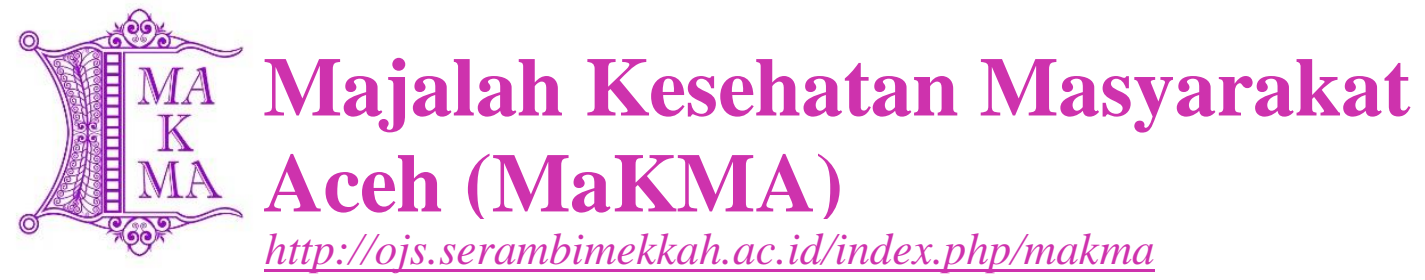

\title{
FAKTOR YANG BERHUBUNGAN DENGAN PERILAKU PENGGUNAAN ALAT PELINDUNG DIRI PADA PEKERJA BAGIAN PRODUKSI PT. SEMEN BOSOWA BANYUWANGI
}

\author{
Maulida Rachmadiyawati ${ }^{1 \bowtie}$, Y. Denny Ardyanto $\mathbf{W}^{2}$ \\ ${ }^{1}$ Departemen Keselamatan dan Kesehatan Kerja, S1 Kesehatan Masyarakat, ${ }^{2}$ PSDKU \\ Universitas Airlangga di Banyuwangi.
}

${ }^{\square}$ Alamat Korespondensi: Jl. Wijaya Kusuma No. 113, Kampus I PSDKU Universitas Airlangga Banyuwangi / maulida-rachmadiyawati.2015@fkm.unair.ac.id / 081259136112

\begin{abstract}
ABSTRAK
Pekerja tidak menggunakan APD (Alat Pelindung Diri) saat bekerja adalah termasuk ke dalam perilaku tidak aman yang dapat meningkatkan risiko keparahan akibat kecelakaan kerja maupun penyakit akibat kerja sehingga dapat menimbulkan kerugian bagi pekerja maupun perusahaan. Saat observasi di PT. Semen Bosowa Banyuwangi, ditemukan 10\% pekerja bagian produksi yang sedang melakukan pekerjaannya saat itu tidak menggunakan APD lengkap diantaranya hanya menggunakan helm safety dan tidak memakai sepatu safety sedangkan yang lain hanya memakai sepatu dan helm safety tanpa memakai masker kain. Tujuan penelitian ini adalah melakukan analisis faktor yang berhubungan dengan perilaku penggunaan APD (Alat Pelindung Diri) pada pekerja bagian produksi di PT. Semen Bosowa Banyuwangi. Penelitian ini termasuk dalam penelitian observasional analitik dengan desain penelitian cross sectional. Sampel pada penelitian ini berjumlah 30 pekerja bagian produksi PT. Semen Bosowa Banyuwangi. Variabel yang diteliti adalah activator (pengetahuan dan motivasi), consequence (punishment), dan perilaku penggunaan APD (Alat Pelindung Diri). Analisis data yang digunakan pada penelitian ini adalah uji koefisien kontingensi untuk menganalisis kuat hubungan antar variabel. Hasil penelitian menunjukkan bahwa hubungan antara pengetahuan dengan perilaku penggunaan APD adalah sangat rendah $(\mathrm{CC}=0,155)$, hubungan antara motivasi dengan perilaku penggunaan APD (Alat Pelindung Diri) adalah rendah $(\mathrm{CC}=0,299)$ dan hubungan antara punishment dengan perilaku penggunaan APD (Alat Pelindung Diri) adalah sangat rendah $(\mathrm{CC}=0,149)$ pada pekerja bagian produksi PT. Semen Bosowa Banyuwangi. Kesimpulan dari penelitian ini adalah faktor activator (pengetahuan dan motivasi) dan consequence (punishment) memiliki hubungan sangat rendah dengan perilaku penggunaan APD (Alat Pelindung Diri) pada pekerja bagian produksi PT. Semen Bosowa Banyuwangi. Berdasarkan hasil penelitian tersebut, disarankan kepada perusahaan dan pekerja untuk meningkatkan perilaku aman menggunakan APD (Alat Pelindung Diri) yaitu dengan cara mengadakan toolbox meeting, observasi perilaku aman, dan pengadaan program reward.
\end{abstract}

Kata Kunci: Activator, Alat Pelindung Diri, Consequence, Perilaku.

Riwayat Artikel

Diterima : 07 Juni 2019

Disetujui : :28 Juli 2019

Dipublikasi : 31 Juli 2019 


\title{
FACTORS RELATED TO BEHAVIOR OF PERSONAL PROTECTIVE EQUIPMENT USAGE IN PRODUCTION WORKERS OF PT. SEMEN BOSOWA BANYUWANGI
}

\begin{abstract}
Workers do not use PPE (Personal Protective Equipment) when working are included in unsafe behavior that can increase the risk of severity due to workplace accidents or work-related diseases so that it can cause harm to workers and companies. When observing at PT. Semen Bosowa Banyuwangi, found that $10 \%$ of production workers who were doing their work at that time did not use complete PPE including only using safety helmets and not wearing safety shoes while others only wearing shoes and safety helmets without wearing masks. The purpose of this study is to analyze the factors related to behavior of PPE (Personal Protective Equipment) usage in production workers at PT. Semen Bosowa Banyuwangi. This study was included in analytic observational research with cross sectional research design. The sample in this study amounted to 30 production workers PT. Semen Bosowa Banyuwangi. The variables studied were activators (knowledge and motivation), consequence (punishment), and behavior of PPE (Personal Protective Equipment) usage. Data analysis used in this study was Contingency Coefficient Test to analyze the strength of a relationship between variables. The results showed that the relationship between knowledge with the behavior of PPE (Personal Protective Equipment) usage is very low $(\mathrm{CC}=0.155)$, the relationship between motivation with the behavior of PPE (Personal Protective Equipment) usage is low $(\mathrm{CC}=0,299)$ and the relationship between punishment with the behavior of PPE (Personal Protective Equipment) usage is very low $(\mathrm{CC}=0.149)$ in production workers at PT. Semen Bosowa Banyuwangi. The conclusion of this study are activator factor (knowledge and motivation) and consequence factor (punishment) have very low relationship with the behavior of PPE (Personal Protective Equipment) usage in production workers at PT. Semen Bosowa Banyuwangi. Based on the results of these studies, it is recommended for companies and workers to increase safe behavior using PPE (Personal Protective Equipment), namely by conducting toolbox meetings, observing safe behavior, and reward programs.
\end{abstract}

Keywords: Activator, Behavior, Consequence, Personal Protective Equipment. 


\section{PENDAHULUAN}

Setiap tempat kerja memiliki berbagai potensi bahaya yang dapat mempengaruhi kesehatan tenaga kerja dan dapat menyebabkan terjadinya kerugian, kerusakan, cedera, sakit, kecelakaan atau mengakibatkan kematian yang berhubungan dengan proses dan sistem kerja. ${ }^{[1]}$ Bahaya ditempat kerja tersebut dapat dikendalikan dengan cara mengikuti hierarki pengendalian bahaya sesuai dengan standar OHSAS 18001:2007, yaitu salah satunya adalah dengan menggunakan Alat Pelindung Diri (APD). ${ }^{[2]}$ APD merupakan suatu alat yang dipakai untuk melindungi diri atau tubuh terhadap bahaya kecelakaan kerja, dimana secara teknis dapat mengurangi tingkat keparahan dari kecelakaan kerja yang terjadi. Peralatan pelindung diri tidak menghilangkan atau mengurangi bahaya yang ada, peralatan ini hanya mengurangi jumlah kontak dengan bahaya dengan cara penempatan penghalang antara tenaga kerja dengan bahaya. $^{[3]}$

Pada umumnya perusahaan telah menerapkan sistem manejemen $\mathrm{K} 3$, yang didalamnya juga terdapat ketentuan dalam penggunaan Alat Pelindung Diri (APD). Hal tersebut tidak didukung penerapannya oleh pekerja yang dibuktikan oleh hasil penelitian yang menunjukkan bahwa terdapat 56\% pekerja memiliki perilaku tidak baik dalam pemakaian APD ketika bekerja, sedangkan sebanyak $44 \%$ pekerja memiliki perilaku baik dalam penggunaan APD selama melakukan pekerjaan. ${ }^{[4]}$ Penelitian lain juga menyebutkan bahwa sebesar $68,1 \%$ responden menunjukkan tindakan penggunaan APD yang kurang baik dan sebesar $31,9 \%$ responden yang menunjukkan tindakan penggunaan APD dengan baik. ${ }^{[5]}$

Bekerja tidak menggunakan APD termasuk ke dalam perilaku tidak aman yang dapat meningkatkan risiko keparahan akibat kecelakaan kerja maupun penyakit akibat kerja sehingga dapat menimbulkan kerugian bagi tenaga kerja maupun perusahaan. Kerugian yang didapatkan oleh tenaga kerja ditunjukkan oleh penelitian yang menemukan bahwa dari 65 responden $86,1 \%$ diantaranya tidak patuh menggunakaan APD dan 49,2\% diantaranya pernah mengalami kejadian kecelakaan kerja. ${ }^{[6]}$ Penelitian lain menyatakan bahwa 14 responden yang tidak menggunakan APD, 5 diantaranya mengalami kecelakaan kerja yaitu jari terpotong, 8 responden mengalami luka robek dan sisanya tertusuk. ${ }^{[7]}$ Beberapa akibat yang dirasakan perusahaan jika terjadi kecelakaan kerja selain dapat menurunkan produktivitas perusahaan adalah kerugian berupa finansial akibat rusaknya produk dan bahan-bahan maupun biaya pengobatan dan santunan yang harus dibayarkan perusahaan bagi tenaga kerja yang mengalami kecelakaan kerja.

Perilaku tenaga kerja terhadap peraturan penggunaan APD (Alat Pelindung Diri) memiliki kemungkinan kecil untuk muncul dengan sendirinya. Pasti ada beberapa variabel penggerak yang dapat membentuk perilaku kerja khususnya dalam penggunaan APD yang diharapkan. Perilaku aman (safe behavior) merupakan suatu bentuk perilaku, maka pendekatan yang dapat dilakukan untuk membentuk suatu perilaku aman yang diharapkan adalah melalui pendekatan perilaku. Salah satunya dengan melakukan pendekatan perilaku yaitu model ABC (Activator Behavior - Consequence). Penggunaan model perilaku $\mathrm{ABC}$ merupakan cara yang tepat untuk menganalisis faktor 
yang berhubungan pada kejadian atau pada suatu perilaku dan model ini dapat digunakan untuk memutuskan rencana tindakan perbaikan. ${ }^{[8]}$

Pada observasi awal di PT. Semen Bosowa Banyuwangi khususnya pada bagian produksi, ditemukan $10 \%$ pekerja bagian produksi yang sedang melakukan pekerjaannya saat itu tidak menggunakan APD lengkap. Pekerja yang berperilaku tidak aman terutama tidak menggunakan APD secara lengkap saat melakukan aktivitas pekerjaan dapat menambah tingkat keparahan akibat kecelakaan kerja yang terjadi. Oleh karena itu penelitian ini dilakukan untuk menganalisis faktor yang berhubungan

\section{METODE}

Penelitian ini merupakan jenis penelitian observasional karena peneliti hanya melakukan pengamatan tanpa memberikan perlakuan. Berdasarkan rancang bangun penelitian, maka penelitian ini merupakan cross sectional study karena penelitian dilakukan pada satu waktu tertentu.

Besar sampel pada penelitian ini diambil dari total populasi yaitu 30 responden yang merupakan pekerja bagian produksi PT. Semen Bosowa

\section{HASIL}

Berdasarkan hasil penelitian diketahui bahwa sebagian besar pekerja bagian produksi berada pada kategori usia 25 - 34 tahun yaitu sebesar 50,0\% dan seluruh pekerja bagian produksi (100\%) berjenis kelamin laki-laki. Hasil analisis menunjukkan bahwa sebagian besar pekerja bagian produksi $(76,7 \%)$ memiliki latar belakang pendidikan SMU diketahui bahwa sebagian besar pekerja pada bagian produksi tergolong pada kelompok masa kerja sedang yaitu pada kategori 6 - 10 tahun sebesar $36,7 \%$. dengan perilaku penggunaan APD pada pekerja bagian produksi di PT. Semen Bosowa Banyuwangi menggunakan teori ABC (Activator, Behavior, Consequence) yaitu faktor activator terdiri dari pengetahuan dan motivasi sedangkan faktor consequence yaitu punishment. Hasil analisis tersebut nantinya akan dapat diketahui faktor apa saja yang dapat mempengaruhi seseorang berperilaku aman, sehingga dapat digunakan sebagai masukan untuk merubah perilaku tenaga kerja yang tidak aman (unsafe behavior) menjadi aman (safe behavior).

Banyuwangi. Waktu penelitian dilakukan pada bulan April 2019. Pengumpulan data mengenai faktor activator (pengetahuan dan motivasi) dan faktor consequence (punishment) dilakukan melalui pengisian kuesioner oleh responden dan dilakukan observasi melalui perilaku penggunaan APD oleh peneliti.

Hasil analisis distribusi frekuensi pengetahuan menunjukkan bahwa mayoritas pekerja bagian produksi $(90,0 \%)$ memiliki pengetahuan yang baik mengenai Alat Pelindung Diri (APD). Hasil analisis distribusi frekuensi motivasi diketahui bahwa mayoritas pekerja $(76,7 \%)$ memiliki tingkat motivasi yang kurang baik dalam penggunaan Alat Pelindung Diri (APD). Hasil analisis distribusi frekuensi motivasi menunjukkan bahwa mayoritas pekerja $(83,3 \%)$ tidak pernah mendapat punishment terkait dengan penggunaan Alat Pelindung Diri (APD). 
Berdasarkan hasil observasi pada pekerja bagian produksi PT. Semen Bosowa Banyuwangi diketahui bahwa sebagian besar pekerja $(56,7 \%)$ telah menggunakan Alat Pelindung Diri (APD) lengkap sesuai dengan sub unit di tempat kerja. [Tabel.1]

Hasil distribusi silang menunjukkan bahwa sebagian besar pekerja memiliki pengetahuan baik dan menggunakan APD lengkap yaitu sebanyak 16 orang $(59,3 \%)$. Nilai contingency coefficient (CC) sebesar 0,155 maka hal ini menunjukkan bahwa hubungan antara pengetahuan dengan perilaku penggunaan APD pada pekerja bagian produksi di PT. Semen Bosowa Banyuwangi adalah sangat rendah.

\section{[Tabel.2]}

Hasil distribusi silang menunjukkan bahwa sebagian besar pekerja tergolong

\section{PEMBAHASAN}

\section{Hubungan Pengetahuan dengan Perilaku Penggunaan APD \\ Pengetahuan adalah hasil} penginderaan manusia atau hasil tahu seseorang terhadap objek melalui indera yang dimilikinya. ${ }^{[9]}$ Berdasarkan hasil penelitian uji kuat hubungan didapatkan nilai contingency coefficient (CC) sebesar 0,155 sehingga dapat ditarik kesimpulan bahwa hubungan antara pengetahuan dan perilaku penggunaan APD pada pekerja bagian produksi PT. Semen Bosowa Banyuwangi adalah sangat rendah. Hal ini juga sejalan dengan penelitian yang menyatakan bahwa tidak terdapat hubungan antara pengetahuan dengan tindakan penggunaan APD pada tenaga kerja. ${ }^{[5]}$

Sebagian besar (90\%) pekerja bagian produksi PT. Semen Bosowa Banyuwangi memiliki informasi dan wawasan yang baik mengenai Alat Pelindung Diri (APD). Namun, tidak memiliki motivasi kurang baik dan menggunakan APD lengkap yaitu sebanyak 15 orang $(65,2 \%)$. Nilai contingency coefficient (CC) sebesar 0,299 maka hal ini menunjukkan bahwa hubungan antara motivasi dengan perilaku penggunaan APD pada pekerja bagian produksi di PT. Semen Bosowa Banyuwangi adalah rendah. [Tabel.3]

Hasil distribusi silang menunjukkan bahwa sebagian besar pekerja mengatakan tidak pernah mendapat punishment dan menggunakan APD lengkap yaitu sebanyak 15 orang $(60,0 \%)$. Nilai contingency coefficient (CC) sebesar 0,149 maka hal ini menunjukkan bahwa hubungan antara punishment dengan perilaku penggunaan APD pada pekerja bagian produksi di PT. Semen Bosowa Banyuwangi adalah sangat rendah. [Tabel.4]

semua pekerja dengan pengetahuan yang baik tersebut dapat menunjukkan perilaku penggunaan APD yang baik di setiap kegiatan produksi yang dilakukan di PT. Semen Bosowa Banyuwangi. Sebagian kecil dari pekerja bagian produksi PT. Semen Bosowa Banyuwangi masih berpendapat bahwa menjaga keselamatan dan kesehatan kerja merupakan tanggungjawab pimpinan dan orang-orang yang ditunjuk saja, sehingga pekerja beranggapan bahwa penggunaan APD bukan merupakan tanggungjawab mereka. Pekerja juga beranggapan bahwa APD hanya digunakan oleh pekerja tertentu yang memiliki risiko sangat tinggi untuk celaka, sehingga pekerja yang merasa dirinya memiliki pekerjaan dengan risiko rendah tidak perlu menggunakan APD lengkap. Hal tersebut dapat diartikan bahwa pekerja yang termasuk dalam kategori memiliki pengetahuan baik tidak berpengaruh secara signifikan 
terhadap penggunaan APD baik lengkap maupun tidak lengkap.

Perilaku tidak selalu dipengaruhi oleh pengetahuan dan sikap positif. Hal ini menunjukkan bahwa perilaku dengan keunikannya dipengaruhi oleh banyak variabel. ${ }^{[10]}$ Sehingga dapat diartikan bahwa pengetahuan yang baik tidak selalu menghasilkan perilaku yang baik khususnya dalam penggunaan APD lengkap. Hal tersebut dapat disebabkan oleh pengetahuan pekerja belum pada tingkatan aplikasi. Pengetahuan secara garis besar dibagi dalam 6 tingkatan pengetahuan yaitu tahu, memahami, aplikasi, analisis, sintesis dan evaluasi. ${ }^{[9]}$ Aplikasi diartikan apabila orang yang telah memahami sesuatu dapat menggunakan atau mengaplikasikan prinsip yang diketahui tersebut pada situasi yang lain. ${ }^{[9]}$ Hal tersebut sejalan dengan penelitian yang menyebutkan bahwa pekerja dengan pengetahuan baik dapat menunjukkan perilaku yang kurang tepat dalam hal penggunaan alat pelindung diri, karena masih terdapat faktor lain yang mendasari timbulnya perilaku tersebut. ${ }^{[11]}$ Berdasarkan uraian diatas dapat disimpulkan bahwa faktor pengetahuan tidak berpengaruh terhadap penggunaan APD pada pekerja bagian produksi PT. Semen Bosowa Banyuwangi.

\section{Hubungan Motivasi dengan Perilaku Penggunaan APD}

Berdasarkan hasil penelitian uji kuat hubungan didapatkan nilai contingency coefficient (CC) sebesar 0,299 sehingga dapat ditarik kesimpulan bahwa hubungan antara motivasi dan perilaku penggunaan APD pada pekerja bagian produksi PT. Semen Bosowa Banyuwangi adalah rendah. Hal ini juga sejalan dengan penelitian yang menunjukkan bahwa motivasi tidak memiliki hubungan yang signifikan dengan kepatuhan menggunakan APD. ${ }^{[12]}$

Pada penelitian ini, motivasi pekerja diketahui melalui pendapat pekerja mengenai hal yang dapat mendorong pekerja untuk menggunakan APD di tempat kerja yang dapat berasal dari internal maupun eksternal yaitu berupa peraturan yang mengikat, pujian, kepercayaan, dan harapan. Hasil penelitian menunjukkan bahwa pekerja yang memiliki motivasi kurang baik dan menggunakan APD lengkap lebih banyak dibandingkan pekerja yang memiliki motivasi baik dan menggunakan APD lengkap. Beberapa pekerja menjawab tidak setuju bahwa pekerja berperilaku aman (menggunakan APD) saat bekerja hanya untuk menghindari sanksi dan teguran dari atasan. Pekerja juga menjawab tidak setuju mengenai keinginan pekerja untuk mendapatkan hadiah atau reward ketika bekerja menggunakan APD. Motivasi sebagai interaksi antara perilaku dan lingkungan atau situasi sehingga dapat meningkatkan, menurunkan atau mempertahankan perilaku. ${ }^{[9]}$ Sehingga, dapat dikatakan bahwa bentuk dari keinginan pekerja untuk mendapat reward dan menghindari sanksi atau teguran merupakan bentuk dari interaksi lingkungan atau situasi dengan perilaku atau yang biasa disebut motivasi. Selanjutnya bagaimana pekerja menyikapi bentuk motivasi tersebut apakah dapat meningkatkan perilaku penggunaan APD, atau menurunkan perilaku tersebut, atau bahkan mempertahan perilaku penggunaan APD yang telah dilakukan. Meskipun tidak ada kebutuhan yang benar dipenuhi, sebuah kebutuhan yang pada dasarnya telah dipenuhi tidak lagi memotivasi. ${ }^{[13]}$ 


\section{Hubungan Punishment dengan Perilaku Penggunaan APD \\ Punishment (hukuman) adalah} salah satu bentuk konsekuensi yang diterima individu atau kelompok sebagai bentuk akibat dari perilaku yang tidak diharapkan. Positive reinforcement dan negative reinforcement memperbesar kemungkinan suatu perilaku untuk muncul kembali sedangkan punishment memperkecil kemungkinan suatu perilaku untuk muncul kembali. ${ }^{[14]}$ Berdasarkan hasil penelitian uji kuat hubungan didapatkan nilai contingency coefficient (CC) sebesar 0,149 sehingga dapat ditarik kesimpulan bahwa hubungan antara punishment dan perilaku penggunaan APD pada pekerja bagian produksi PT. Semen Bosowa Banyuwangi adalah sangat rendah. Hal ini juga sejalan dengan penelitian yang menunjukkan bahwa tidak terdapat hubungan bermakna antara punishment dengan kepatuhan menggunakan APD yang merupakan salah satu bentuk dari safe behavior tenaga kerja. ${ }^{[15]}$

Faktor punishment pada penelitian ini merupakan bentuk dari consequence yang timbul akibat pekerja berperilaku tidak aman dalam menggunakan APD ketika bekerja yaitu dalam bentuk pemberian sanksi berupa surat peringatan dan pemotongan insentif. Distribusi pekerja yang mengatakan tidak pernah mendapat

\section{KESIMPULAN DAN SARAN}

Sebagian besar pekerja bagian produksi PT. Semen Bosowa Banyuwangi telah menggunakan APD lengkap sesuai dengan sub unit tempat kerja, pekerja memiliki pengetahuan baik mengenai APD, memiliki tingkat motivasi yang kurang baik dalam penggunaan APD, dan tidak pernah mendapat punishment terkait dengan penggunaan APD. punishment dan menggunakan APD lengkap lebih banyak dibanding pekerja yang mengatakan pernah mendapat punishment dan menggunakan APD lengkap. Beberapa pekerja mengatakan bahwa pekerja pernah mendapat teguran ataupun sanksi lain yang diterapkan oleh PT. Semen Bosowa Banyuwangi akibat berperilaku tidak aman atau menggunakan APD tidak lengkap. Ada beberapa pekerja yang mengatakan pernah mendapat punishment dan tetap menggunakan APD tidak lengkap. Hal tersebut dapat terjadi karena punishment tersebut hanya membuat pekerja tertekan sementara dan tidak mampu merubah perilaku secara permanen. Hal ini sesuai dengan teori yang mengatakan bahwa meskipun punishment dapat menghilangkan perilaku yang tidak diharapkan secara lebih cepat, perilaku yang mendapat punishment cenderung hanya tertekan secara sementara dan bukan diubah secara permanen. ${ }^{[13]} \mathrm{Hal}$ tersebut dapat disimpulkan bahwa pekerja yang pernah mendapat punishment merasa tertekan sehingga perilaku penggunaan APD lengkap yang dilakukan hanya bersifat sementara, selanjutnya pekerja akan berperilaku tidak aman.

Hasil penelitian menunjukkan bahwa hubungan antara faktor activator yaitu pengetahuan dengan perilaku penggunaan APD adalah sangat rendah, hubungan antara faktor activator yaitu motivasi dengan perilaku penggunaan APD (Alat Pelindung Diri) adalah rendah dan hubungan antara faktor consequence yaitu punishment dengan perilaku penggunaan APD (Alat Pelindung Diri) adalah sangat rendah pada pekerja bagian produksi PT. Semen Bosowa Banyuwangi. 
Berdasarkan hasil penelitian tersebut diharapkan perusahaan mengadakan toolbox meeting untuk pekerja sebelum melakukan pekerjaan yang menjelaskan mengenai bahaya serta cara penanggulangannya supaya pekerja berperilaku aman saat bekerja khususnya menggunakan APD lengkap sesuai dengan jenis pekerjaannya. Harapan lainnya adalah diadakannya observasi mengenai perilaku penggunaan APD ketika bekerja secara konsisten dan terus menerus oleh masing-masing section head yang

\section{DAFTAR PUSTAKA}

1. Irzal, 2016. Dasar-Dasar Kesehatan dan Keselamatan Kerja: Edisi Pertama. [e-book] Jakarta: Kencana. Tersedia di: https://books.google.co.id

2. OHSAS, 2007. Occupational Health snd Safety Assessment Series 18001: Occupational Health and Safety Management Systems Requirements. Tersedia di: http://www.aims.org.pk/wpcontent/uploads/2014/08/OHSAS18001-2007-Standards.pdf

Oktober 2018].

3. Suma'mur, P. K., 2009. Higiene Perusahaan dan Kesehatan Kerja (Hiperkes). Jakarta: CV Sagung Seto.

4. Brito, G.T., 2015. Analisis Aspek Pembentuk Budaya K3 dengan Kepatuhan Penggunaan APD Pada Pekerja Produksi Resin di Sidoarjo. The Indonesian Journal of Occupational Safety and Health, [ejournal] 4(2): pp.1-10. Tersedia di: <https://ejournal.unair.ac.id/IJOSH/article/vi ew/1744/1309> [diakses tanggal 27 Oktober 2018].

5. Repi, A.A., Josephus, J., dan Rattu, A.J.M., 2016. Hubungan antara merupakan bagian dari inspeksi mingguan, sehingga pekerja tidak mengulangi lagi perilaku tidak aman yaitu menggunakan APD tidak lengkap. Selanjutnya pekerja diharapkan memiliki motivasi untuk melakukan perilaku penggunaan APD lengkap seterusnya dengan diadakannya program reward atau penghargaan oleh perusahaan dalam bentuk penilaian kinerja bagi pekerja yang patuh dalam menggunakan APD lengkap.

Pengetahuan dan Sikap dengan Tindakan Penggunaan Alat Pelindung Diri Pada Tenaga Kerja di PT Tropica Cocoprima Desa Lelema Kecamatan Tumpaan Kabupaten Minahasa Selatan. [ejournal] 5(1): pp.1-10. Tersedia di: $<$ https://ejournal.unsrat.ac.id/index. php/kesmas/article/view/12681> [diakses tanggal 27 Oktober 2018].

6. Barizqi, I.N., 2015. Hubungan Antara Kepatuhan Penggunaan APD dengan Kejadian Kecelakaan Kerja Pada Pekerja Bangunan PT. Adhi Karya Tbk Proyek Rumah Sakit Telogorejo Semarang. Skripsi. Universitas Negeri Semarang.

7. Utami, S.D., 2006. Hubungan Antara Pemakaian Alat Pelindung Tangan dengan Kecacatan Akibat Kecelakaan Kerja di PT. Purinusa Eka Persada Semarang Tahun 2005. Skripsi. Universitas Negeri Semarang.

8. Geller, E. Scott, 2001. Working Safe : How to Help People Actively Care for Health and Safety. Florida : Lewis Publisher.

9. Notoatmodjo, S., 2010. Promosi Kesehatan Teori dan Aplikasinya. Jakarta: Rineka Cipta.

10. Maulana, H. D. J., 2009. Promosi 
Kesehatan. Jakarta: EGC.

11. Rachmansyah, A. H., 2016. Analisa Perilaku Memakai APD Sarung

Tangan Berdasarkan Model Perilaku ABC pada Tenaga Kerja Bagian Penimbangan Serbuk Menthol di PT Coronet Crown Sidoarjo. Skripsi. Universitas Airlangga.

12. Putri, K. D. S., 2017. Analisis Faktor yang Berhubungan dengan Kepatuhan Menggunakan Alat Pelindung Diri. The Indonesian Journal of Occupational Safety, Health and Environment, [e-journal] 6(3): pp.1-10. Tersedia di: $<$ https://ejournal.unair.ac.id/IJOSH/article/vi ew/9689/pdf> [diakses tanggal 19 Mei 2019]

13. Robbins, S. P., dan Judge, T. A., 2008. Edisi 12: Perilaku Organisasi
(Penerjemah Diana Angelica, dkk). Jakarta: Salemba Empat.

14. Fleming, M. \& Lardner, R., 2002. Strategies to Promote Safe Behaviour As Part Of A Health and Safety Management System. Tersedia di www.hse.gov.uk/research/crr_pdf/2 002/crr02430.pdf

15. Retnani, N.D. dan Ardyanto, D., 2013. Analisis Pengaruh Activator dan Consequence Terhadap Safe Behavior Pada Tenaga Kerja di PT. Pupuk Kalimantan Timur Tahun 2013. The Indonesian Journal of Occupational Safety and Health, [ejournal] 2(2): pp.1-11. Tersedia di: <journal.unair.ac.id/filerPDF/k3e46 0303427full.pdf> [diakses tanggal 19 Mei 2019]. 


\section{LAMPIRAN}

Tabel [1]. Distribusi Frekuensi Perilaku Penggunaan APD Pekerja Bagian Produksi di PT. Semen Bosowa Banyuwangi

\begin{tabular}{lcc}
\hline Perilaku Penggunaan APD & Jumlah & Persentase (\%) \\
\hline Lengkap & 17 & 56,7 \\
Tidak Lengkap & 13 & 43,3 \\
Total & 30 & 100 \\
\hline
\end{tabular}

Sumber: Data Primer 2019

Tabel [2]. Hubungan Pengetahuan dengan Perilaku Penggunaan APD Pekerja Bagian Produksi di PT. Semen Bosowa Banyuwangi

\begin{tabular}{lcccccccc}
\hline & \multicolumn{9}{c}{ Perilaku Penggunaan APD } & & \\
\multicolumn{1}{c}{ Pengetahuan } & \multicolumn{2}{c}{ Lengkap } & \multicolumn{2}{c}{ Tidak } & Total & CC \\
& n & $\mathbf{\%}$ & $\mathbf{n}$ & $\mathbf{\%}$ & $\mathbf{N}$ & $\mathbf{\%}$ & \\
\hline Baik & 16 & 59,3 & 11 & 40,7 & 27 & 100 & \\
Cukup & 1 & 33,3 & 2 & 66,7 & 3 & 100 & 0,155 \\
Jumlah & 17 & 56,7 & 13 & 43,3 & 30 & 100 & \\
\hline
\end{tabular}

Sumber: Data Primer 2019

Tabel [3]. Hubungan Motivasi dengan Perilaku Penggunaan APD Pekerja Bagian Produksi di PT. Semen Bosowa Banyuwangi

\begin{tabular}{|c|c|c|c|c|c|c|c|}
\hline \multirow{3}{*}{ Motivasi } & \multicolumn{6}{|c|}{ Perilaku Penggunaan APD } & \multirow{3}{*}{$\mathbf{C C}$} \\
\hline & \multicolumn{2}{|c|}{ Lengkap } & \multicolumn{2}{|c|}{$\begin{array}{c}\text { Tidak } \\
\text { Lengkap }\end{array}$} & \multicolumn{2}{|c|}{ Total } & \\
\hline & $\mathbf{n}$ & $\%$ & $\mathbf{n}$ & $\%$ & $\mathbf{N}$ & $\%$ & \\
\hline Baik & 2 & 28,6 & 5 & 71,4 & 7 & 100 & \\
\hline Kurang Baik & 15 & 65,2 & 8 & 34,8 & 23 & 100 & 0,299 \\
\hline Jumlah & 17 & 56,7 & 13 & 43,3 & 30 & 100 & \\
\hline
\end{tabular}

Sumber: Data Primer 2019

Tabel [4]. Hubungan Kebutuhan Selamat dengan Perilaku Penggunaan APD Pekerja Bagian Produksi di PT. Semen Bosowa Banyuwangi

\begin{tabular}{|c|c|c|c|c|c|c|c|}
\hline \multirow{3}{*}{ Punishment } & \multicolumn{6}{|c|}{ Perilaku Penggunaan APD } & \multirow{3}{*}{$\mathrm{CC}$} \\
\hline & \multicolumn{2}{|c|}{ Lengkap } & \multicolumn{2}{|c|}{$\begin{array}{c}\text { Tidak } \\
\text { Lengkap }\end{array}$} & \multicolumn{2}{|c|}{ Total } & \\
\hline & $\mathbf{n}$ & $\%$ & $\mathbf{n}$ & $\%$ & $\mathbf{N}$ & $\%$ & \\
\hline Pernah & 2 & 40,0 & 3 & 60,0 & 5 & 100 & \\
\hline Tidak Pernah & 15 & 60,0 & 10 & 40,0 & 25 & 100 & 0,149 \\
\hline Jumlah & 17 & 56,7 & 13 & 43,3 & 30 & 100 & \\
\hline
\end{tabular}

Sumber: Data Primer 2019 